\title{
Levantamentos eletromagnéticos para água subterrânea em Campina Grande, Paraíba, Brasil
}

Oderson A. de Souza Filho ${ }^{1}$, Nitzschia R. R. Domingos ${ }^{2}$, Roberto G. de Oliveira ${ }^{2}$, Manoel J. de T. G. Galvão ${ }^{2}$, Geysson de A. Lages $^{2},{ }^{1}$ (NUBA/SUREG-SP/CPRM), ${ }^{2}$ (SUREG/RE/CPRM)

Copyright 2016, SBGf - Sociedade Brasileira de Geofísica

Este texto foi preparado para a apresentação no VII Simpósio Brasileiro de Geofísica Ouro Preto, 25 a 27 de outubro de 2016. Seu conteúdo foi revisado pelo Comitê Técnico do VII SimBGf, mas não necessariamente representa a opinião da SBGf ou de seus associados. É proibida a reprodução total ou parcial deste material para propósitos comerciais sem prévia autorização da SBGf.

\section{Resumo}

$\mathrm{Na}$ região de Campina Grande prevalecem aquíferos fraturados do embasamento Pré-cambriano. A produtividade é muito baixa, com vazões esperadas de 1 a $10 \mathrm{~m} 3 / \mathrm{h}$ e condutividade elétrica acima de $150 \mathrm{mS} / \mathrm{m}$. Esta condutividade, em termos de salinidade, é superior ao limite de potabilidade para consumo humano sem tratamento. Caminhamentos eletromagnéticos com o PROMIS e EM-34 possibilitaram a identificação de estruturas permissíveis, subjacentes a aluviões e respectivos intervalos de condutividade elétrica. O processamento baseou-se na identificação de anomalias características de estruturas planares, verticalizadas e inclinadas, e comparações com modelos de inversão utilizando-se a técnica Occam com Gradientes Conjugados.

\section{Introdução}

Em virtude da seca prolongada dos últimos três anos, tornou-se preocupante o suprimento de água para Campina Grande (PB) e municípios vizinhos. A região é abastecida pelo Açude Boqueirão, distante $42 \mathrm{~km}$ e cujos níveis declinaram $12 \%$ do volume disponível em janeiro de 2016 (cerca de 49,6 milhões $\mathrm{m}^{3}$ - Fonte AESA/PB). Em março, a CPRM foi convocada para avaliar alternativas de abastecimento hídrico e direcionou o atendimento a comunidades fora das sedes municipais. Os trabalhos consistiram de estudos hidrogeológicos, estruturais e geofísicos focados em aquíferos fraturados com coberturas aluvionar ou elúvio-coluvionar.

A Região Metropolitana de Campina Grande-RMCG possui cerca de 630 mil habitantes e localiza-se no Planalto da Borborema, parte central do estado da Paraíba. A pesquisa abrangeu $594 \mathrm{~km}^{2}$ desta região. (Figura 1).

A geologia compreende ortognaisses paleoproterozoicos, unidades neoproterozoicas Cariris Velhos (ortognaisses, migmatitos e muscovita-biotita gnaisses), São Caetano (rochas calciossilicáticas, xistos), granitoides e milonitos variados. (Rodrigues et al. 2011).

Um banco de dados georreferenciado foi estruturado, contemplando a geologia estrutural, hidrogeologia, aerogeofísica magnetométrica e radiométrica; imagens orbitais e modelos digitais de terreno. $\mathrm{E}$ foi possível: a) Selecionar áreas para levantamentos geofísicos;

b) Reconhecimento hidrogeológico regional;

c) Avaliação de sistemas de abastecimentos locais e soluções alternativas.

Apresentamos os resultados preliminares do processamento dos dados eletromagnéticos terrestres.

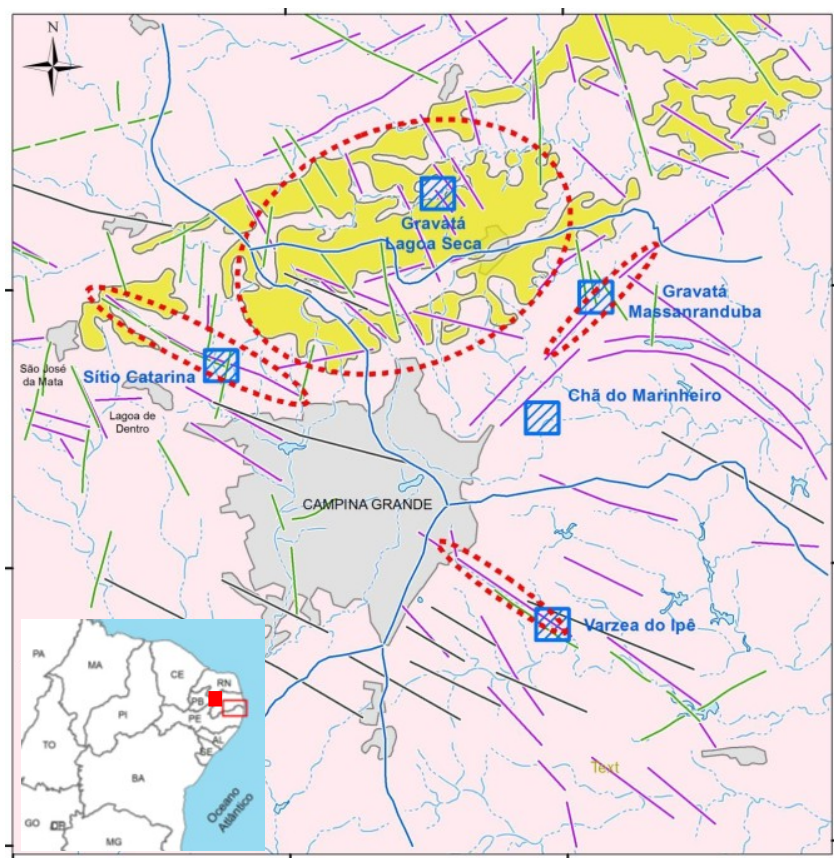

Figura 1 - Localização da área pesquisada no entorno de Campina Grande. Domínios: cristalino -rosa, cobertura colúvio-eluvionar - amarelo, Sedes municipais - cinza.

\section{Metodologia/ Problema Investigado}

O método eletromagnético utilizado sozinho ou em conjunto com outros métodos geofísicos são reconhecidamente úteis na exploração de aquíferos fraturados (van Dongen and Woodhouse, 1994, Palacky et al., 1981) e empregados também na Região Nordeste do Brasil (Oliveira et al., 2002, Pinéo et al., 2013). É possível a interpretação da espessura de aluviões e outras coberturas e localização de zonas fraturadas preenchidas com água.

Foram utilizados os equipamentos EM-34 (Geonics ${ }^{\circledR}$ ) e PROMIS (IRIS Instruments $\circledR$ ) preferencialmente nos mesmos caminhamentos. Os equipamentos baseiam-se na teoria de que um campo primário ao se propagar no subsolo gera correntes elétricas eddy currents, que ao interagir com feições geológicas condutoras (água, 
alguns minerais metálicos, argilas) produzem um campo magnético secundário passível de ser medido.

O PROMIS e o EM-34 são compostos basicamente por dois sensores Transmissor-Tx e Receptor-Rx, módulos dos controle e de energia e cabos de comunicação. No sistema $\mathrm{Tx}$, campos eletromagnéticos alternados (campos primários) são gerados a diferentes frequências por uma bobina. O receptor do PROMIS é multifrequencial e contém três bobinas em arranjos perpendiculares entre si, considerando-se as direções: Zvertical; X-horizontal, ao longo do caminhamento; Yhorizontal, transversal à direção $X$. A separação Tx-Rx é definida por cabos de $20 \mathrm{~m}$ a $400 \mathrm{~m}$.

São medidas as porcentagens das componentes em fase-Ip e quadratura-Q do campo total-H (campos primário+secundário) nas três direções $\mathrm{Hz}, \mathrm{Hx}$ e Hy. Até dez frequências podem ser habilitadas, de $110 \mathrm{~Hz}$ a $56.320 \mathrm{~Hz}$. Neste trabalho, a separação Tx-Rx foi s50m e $\mathrm{s} 100 \mathrm{~m}$, com arranjo de bobinas horizontais coplanares (dipolo magnético vertical), com leituras a cada $10 \mathrm{~m}$.

O EM-34 foi operado com arranjos coplanares horizontal e vertical, nas separações $\mathrm{s} 20 \mathrm{~m}$ e $\mathrm{s} 40 \mathrm{~m}$. As medidas são em condutividade aparente (mS/m) (McNeill, 1980).

Os dados de cada levantamento foram avaliados quanto à qualidade da aquisição, que inclui ruídos sistemáticos (baixa potência do transmissor), movimentações bruscas ou inclinações excessivas dos sensores Tx ou Rx e fontes antrópicas (cerca, objeto metálico, rede elétrica...). Os dados espúrios são eliminados. Fatores de correções de inclinações foram aplicados (Milson et al., 2003).

Cinco localidades foram investigadas nos municípios de Campina Grande (Fazenda Catarina), Lagoa Seca (Sítio Gravatá) e Massaranduba (Gravatá, Chã do Marinheiro e Várzea do Ipê) (Figura 1). Os levantamentos totalizaram: 4.200 metros lineares com o PROMIS; 11.160 metros lineares com o EM-34.

Existem três alvos hidrogeológicos a serem investigados e seu respectivo modelo geofísico:

a) Aluvião: representado por um condutor superficial, prismático horizontalizado e largo (máximo de largura $200 \mathrm{~m} \times 5 \mathrm{~m}$ de espessura $\times$ 5,000 m de comprimento);

b) Zona fraturada com água: um condutor discreto $(0,5$ a $20 \mathrm{~m}$ de largura $\times 50 \mathrm{~m}$ de profundidade $\mathrm{x}$ de 0,01 a 0,1 $m$ espessura), representado por placas finas, verticalizadas ou inclinadas;

c) Sistemas complexos aluvião - manto de intemperismo zonas fraturadas: conjunto de condutores horizontais e verticais e de difícil representação por superposição de poliedros e placas.

A interpretação dos dados e dos possíveis alvos de interesse foi baseada em análises qualitativas das anomalias (condutividade elétrica aparente, componentes Ip e Q), ou comparando-os aos resultados de simulações diretas e de modelos de inversão.

As modelagens diretas para arranjos com bobinas horizontais (Telford et al., 1984, Palacky et al., 1981) mostram: as fraturas condutivas verticalizadas tendem a apresentar anomalias negativas de Ip e Q sobre a fonte causativa, ladeada por "ombreiras" com valores positivos. Fraturas inclinadas apresentam deslocamento da anomalia central negativa e ombreira maior para o sentido de mergulho da estrutura. Aluviões (corpos horizontalizados rasos) ou fraturas verticalizadas muito próximas entre si tendem a apresentar anomalias no padrão em "W", centralizadas sobre os alvos. Variações nos padrões ocorrerão devido ao arranjo, espaçamento e características do alvo (dimensão, profundidade e condutividade).

Na técnica de modelagem inversa, foi aplicado aos dados reais um modelo inicial de camadas de espessura e resistividade iguais - até 15 camadas entre 6 e $13 \mathrm{~m}$ e resistividade 100 Ohm.m - O algoritmo baseia-se numa variação da técnica Occam - Conjugate Gradient (PetrosEikon, 2011) - O modelo final é gerado após iterações com variações suaves e conjugadas dos parâmetros petrofísicos de espessura, resistividade elétrica e permeabilidade magnética, mas respeitando-se a mínima diferença entre os dados reais e estimados. Camadas com propriedades físicas semelhantes podem ser unificadas para se criar modelos mais discretos e a resistividade varia segundo limites impostos. O objetivo é criar modelos que identifiquem as zonas condutivas associadas às águas e correlaconá-las aos níveis em poços e cacimbas.

\section{Resultados}

\section{Fazenda Catarina-Novobodocongó, Campina Grande}

O local é um vale orientado NW-SE, com mais de $8 \mathrm{~km}$ de extensão. Os levantamentos foram realizados transversalmente ao vale, onde possui sua maior largura $(45 \mathrm{~m})$ e próximo a um "cotovelo" da drenagem. A cobertura sedimentar é um misto de colúvio e alúvio, arenoso grosseiro, e espessura não excedendo $2,5 \mathrm{~m}$. Afloramentos no leito indicam o substrato de augen granito-gnaisse, com foliação verticalizada, orientada EW. Há três famílias de fraturas: Fr.1-tração (350/86-90), de moderada a larga abertura entre paredes; Fr.2cisalhantes $(180 / 60 ; 355 / 54-70)$, com estreita abertura entre paredes; Fr.3- com estreitas aberturas (059/60; 240/80). As drenagens subsidiárias orientam-se ao longo da foliação e de lineamentos orientados N-S.

O PROMIS foi utilizado com o cabo de $50 \mathrm{~m}$. No levantamento a Leste (Figura 3), a planície aluvionar ocorre entre $\mathrm{X}-160 \mathrm{~m}$ e $\mathrm{X}-270 \mathrm{~m}$. Dois meandros abandonados localizam-se em X-210 m e X-260 m. No modelo geofísico, a zona entre o aluvião e rocha alterada subjacente apresenta condutividade a partir de $30 \mathrm{mS} / \mathrm{m}$ e máximo de $200 \mathrm{mS} / \mathrm{m}$, e estende-se da superfície até $10 \mathrm{~m}$ de profundidade. 


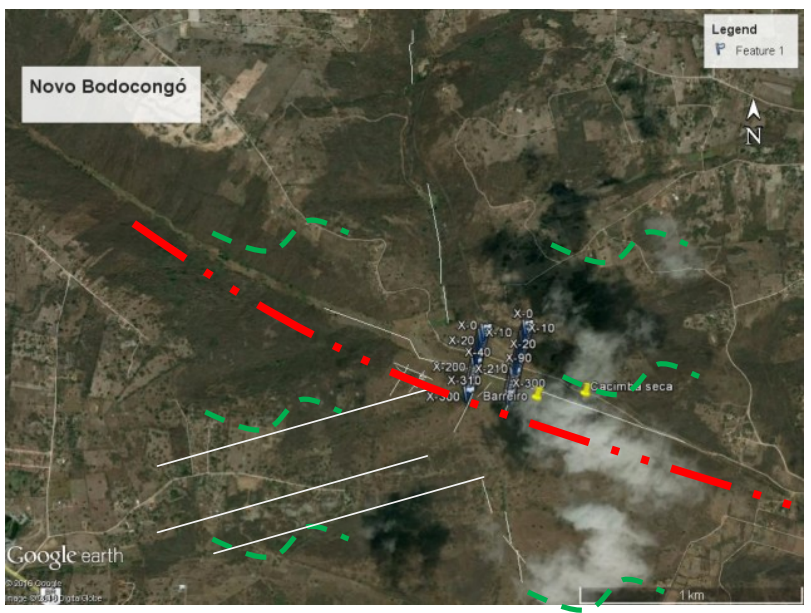

Figura 2 - Caminhamentos EM-34 e PROMIS em vale orientado NW-SE no Sítio Catarina, Campina Grande. Lineamentos em traços branco e vermelho, foliação em verde. Imagem Google Earth.

No gráfico das componentes em fase-lp e quadratura-Op para as frequências $3.520 \mathrm{~Hz}$ e $7.040 \mathrm{~Hz}$, nas posições $\mathrm{X}-180 \mathrm{~m}$ e X-280 m ocorrem duas anomalias negativas, que são indicativas de zonas fraturadas, sendo a primeira destas abaixo do aluvião, a de maior potencial hídrico. Outra anomalia em X-125 m é duvidosa por se encontrar próximo a duas cercas de arame farpado. A proximidade de $10 \mathrm{~m}$ entre as cercas pode causar acoplamento elétrico com os sensores e gerar falsas anomalias.

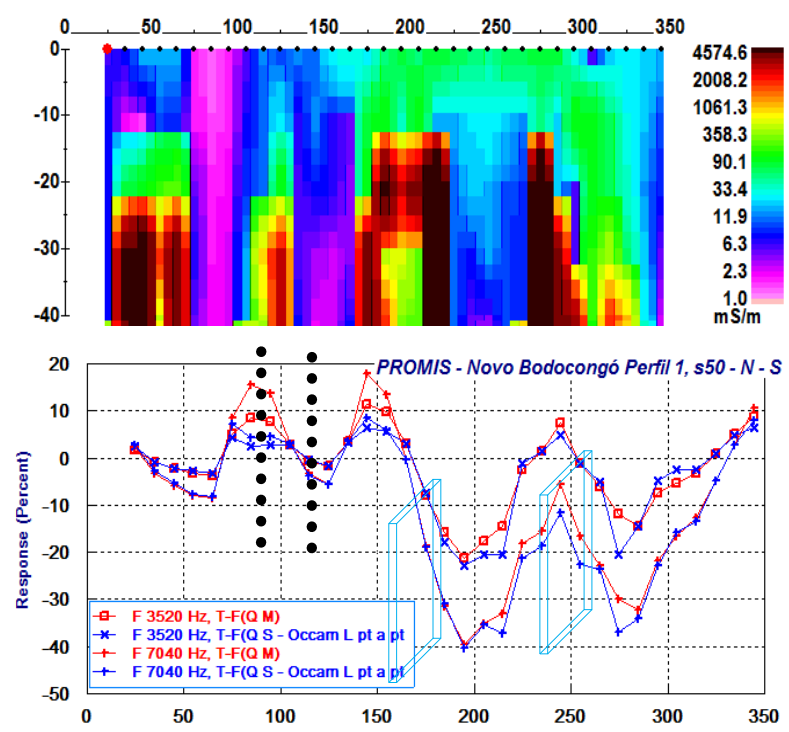

Figura 3 - Sítio Catarina, perfil 1: a) Seção do modelo de inversão Occam aplicado aos dados; b) comparativo do bom ajuste entre dados reais e calculados (erro $<5 \%$ em muitos pontos). Fraturas - retângulo, cerca - pontilhado preto.

O EM-34 mostra um notável aumento de condutividade no aluvião (configuração de dipolo horizontal, $65 \mathrm{mS} / \mathrm{m}$ cabo de $20 \mathrm{~m}$; e $40 \mathrm{mS} / \mathrm{m}$ - cabo de $40 \mathrm{~m}$ ), em relação às encostas com exposição de rochas (em torno de 20 $\mathrm{mS} / \mathrm{m}$ ) (Figura 4). Este aumento da condutividade está relacionado com a presença de areias saturadas com água e níveis argilosos no aluvião.

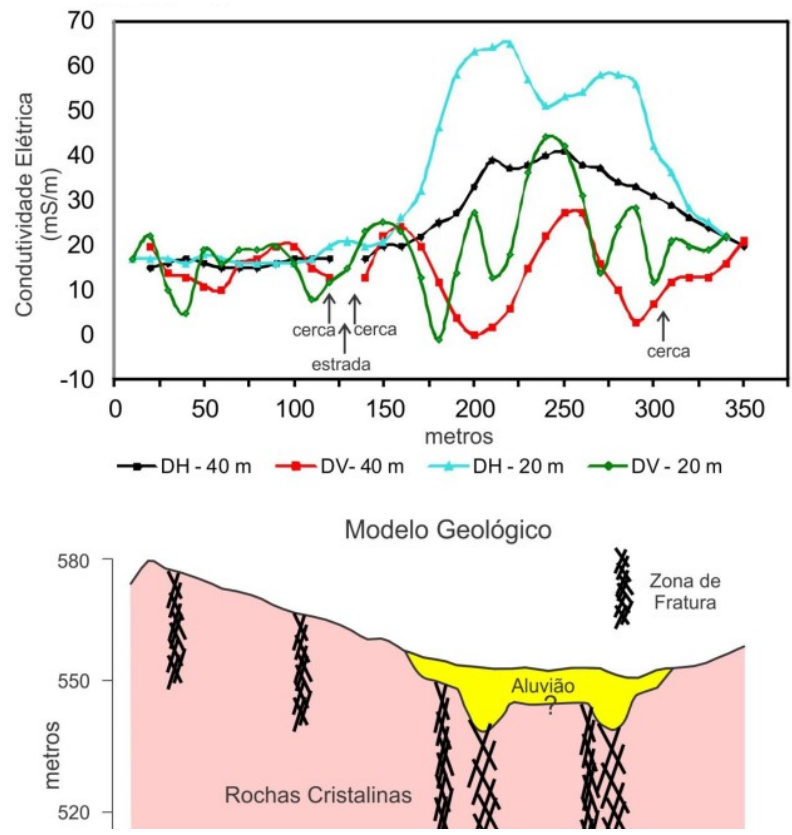

Figura 4 - Dados, interpretação e modelo geológico do Perfil 1 no Sítio Catarina.

Os picos negativos observados na configuração de dipolo vertical indicam duas zonas de fraturas hidrogeologicamente favoráveis. A continuidade das estruturas em profundidade é indicada pela superposição das assinaturas nos cabos de 20 e $40 \mathrm{~m}$ nas posições 200 e $300 \mathrm{~m}$.

No segundo levantamento a Oeste (Figura 5a), o aluvião localiza-se entre X-80 m e X-180 m, sendo bem delimitado no gráfico das componentes em fase-Ip e quadratura- $Q$ e no modelo geofísico de inversão.

No modelo de inversão (Figura $5 b$ ), o aluvião e manto de alteração abaixo deste possui condutividade de $40 \mathrm{mS} / \mathrm{m}$ a $158,4 \mathrm{mS} / \mathrm{m}$ e espessura máxima de $5 \mathrm{~m}$. O substrato pouco alterado e fraturado pode estar associado a valores entre $4.4 \mathrm{mS} / \mathrm{m}$ e $13,6 \mathrm{mS} / \mathrm{m}$. O substrato com rocha sã e não fraturado está delineado no modelo de inversão de X-20 m a X-60 m, e condutividade menor que $1,6 \mathrm{mS} / \mathrm{m}$. Máximos de condutividade (> $600 \mathrm{mS} / \mathrm{m}$ ) abaixo do aluvião e, associados a picos negativos no gráfico Ip $\times \mathrm{Q}$, são interpretados como zonas favoráveis a água subterrânea. Uma provável zona de rocha alterada ocorre entre X-230 m e X250 m, sendo de importância secundária, pois aparentemente não está associada a fraturas subjacentes. 
a)

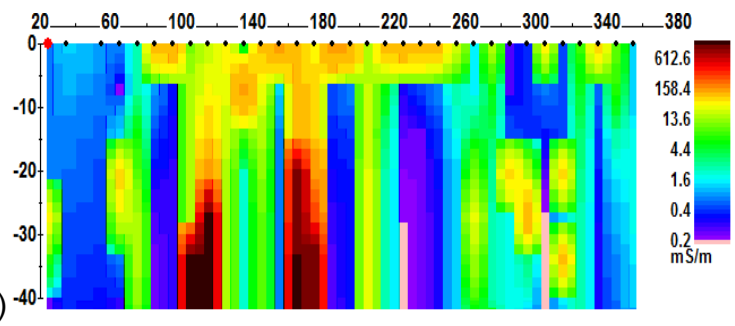

b)

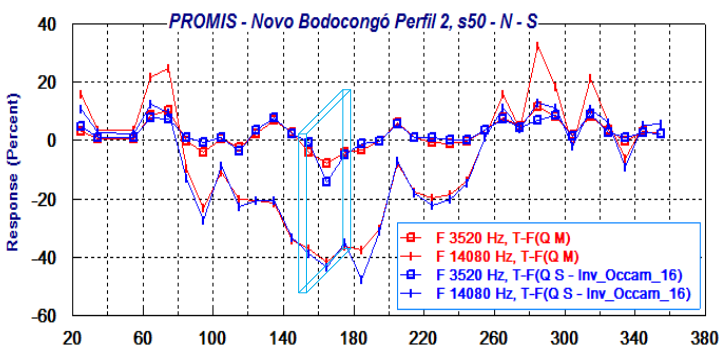

Figura 5 - Sítio Catarina, perfil 2: a) modelo de inversão Occam aplicado aos dados; b) comparativo de bom ajuste entre dados reais e os calculados pelo modelo Occam (erro $<5 \%$ em muitos pontos). Fratura - retângulo.

Os dados do EM-34 no Perfil 2 indicam os mesmos padrões de condutividade elétrica (Figura 6). Os picos negativos medidos na configuração de dipolo vertical com o cabo de $40 \mathrm{~m}$ demonstra a continuidade das estruturas identificadas no Perfil1. Neste caso, as fraturas foram interpretadas nas posições 100 e $160 \mathrm{~m}$. Nos dois perfis também se observa fraturas discretas nas encostas dos vales. Nesta situação, como os picos negativos são observados apenas no cabo de 20 metros (dipolo vertical), as estruturas não devem ser profundas.

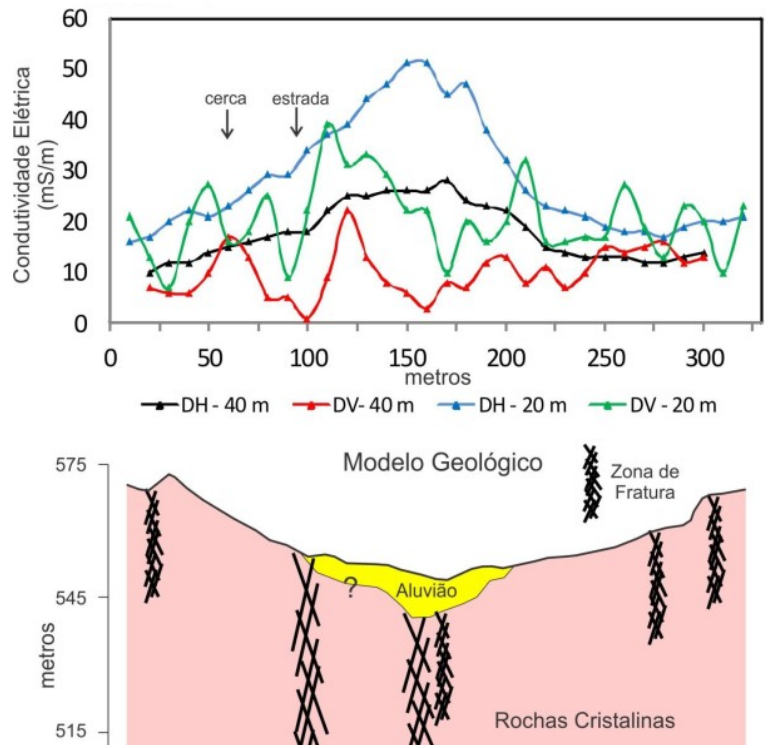

Figura 6 - Dados, interpretação e modelo geológico do Perfil 2 no Sítio Catarina.

\section{VÁRZEA DO IPÊ, MUNICÍPIO DE MASSARANDUBA}

Região de colinas, destacando-se um vale encaixado na estrutura principal NW-SE, contendo depósito aluvionar com até $3 \mathrm{~m}$ de espessura. As ravinas evoluem a partir do padrão losangular de fraturamentos e foliação. Apresentaremos um perfil transversal à estrutura principal e outro longitudinal, dentro do aluvião. O substrato é um monzonito com foliação de fluxo verticalizada orientada NNW-SSE. Fraturas de cisalhamento de médio mergulho orientam-se NW-SE e NE-SW, com estreita abertura entre paredes. Falhas cisalhantes possuem direção NESW (330/20;105/60).

Em imagens Google Earth (Figura 6), observam-se a estrutura principal NW-SE e fraturas nas direções NNWSSE, WNW-ESSE, N40-55E e N40-50W. Feições de "panelas" são observadas nas encostas, em cruzamentos de ravinas encaixadas, sendo prováveis fontes de recarga para o aquífero fraturado.

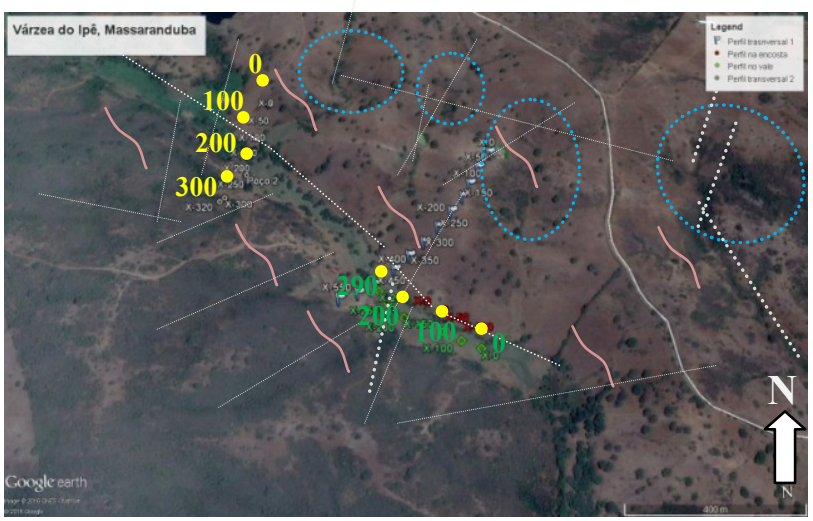

Figura 6 - Várzea do Ipê. Aspectos geomorfológicos e estruturais. Perfil transversal - numeração amarela e longitudinal - numeração verde. Encontro de ravinas azul, lineamentos - traço branco, foliação - rosa.

O levantamento transversal ao vale foi realizado no cruzamento de duas ravinas com o riacho principal, $O$ arranjo do PROMIS foi com s50 m entre sensores e o EM-34 com s40 m. O objetivo era confirmar as estruturas ao longo do vale e o nível de água e a salinidade em poço $50 \mathrm{~m}$ a leste de X-240 m. Uma elevação de aproximadamente $3 \mathrm{~m}$ de altura divide o aluvião principal (posições X-125m a X-180) e o aluvião secundário (entre $\mathrm{X}-240 \mathrm{~m}$ e X-305 m).

As anomalias dos aluviões são as de maior amplitude e extensão lateral. Mas em X-115m, X-145 m, X-285 e X$305 \mathrm{~m}$ há anomalias negativas secundárias, restritas e de menor amplitude, que são indicativas de fraturas subjacentes ao aluvião. (Figura 7a).

Pelo modelo de inversão Occam (Figura 7b,c), os aluviões relacionam-se a condutividades de $56 \mathrm{mS} / \mathrm{m}$ a $121 \mathrm{mS} / \mathrm{m}$, com espessuras até $7 \mathrm{~m}$ no aluvião principal e $5 \mathrm{~m}$ no segundo aluvião. Nas posições X-90 m, X-110 m, $\mathrm{X}-275 \mathrm{~m}$ são visualizadas zonas discretas de alta condutividade (108 mS/m a $240 \mathrm{mS} / \mathrm{m})$ e jazem entre $8 \mathrm{~m}$ e $30 \mathrm{~m}$ de profundidade. Tais feições são interpretadas 
como prováveis estruturas permissíveis para água subterrânea. $\mathrm{Na}$ base destas estruturas ocorre um nível de alta condutividade ( $>240 \mathrm{mS} / \mathrm{m}$ ) que pode indicar acúmulos de água subterrânea no limite rocha alterada e rocha sã. O substrato não alterado está representado nos trechos iniciais e em X-200 m, possuindo baixa condutividade $(<4 \mathrm{mS} / \mathrm{m})$. Os intervalos de condutividade interpretados para a presença de água subterrânea a partir do modelo geofísico são compatíveis com medições em poço em X-240 m (vazão de $3,8 \mathrm{~m}^{3} / \mathrm{h}$ e condutividade de $320 \mathrm{mS} / \mathrm{m}$ ) e poços nas vizinhanças (380 mS/m).
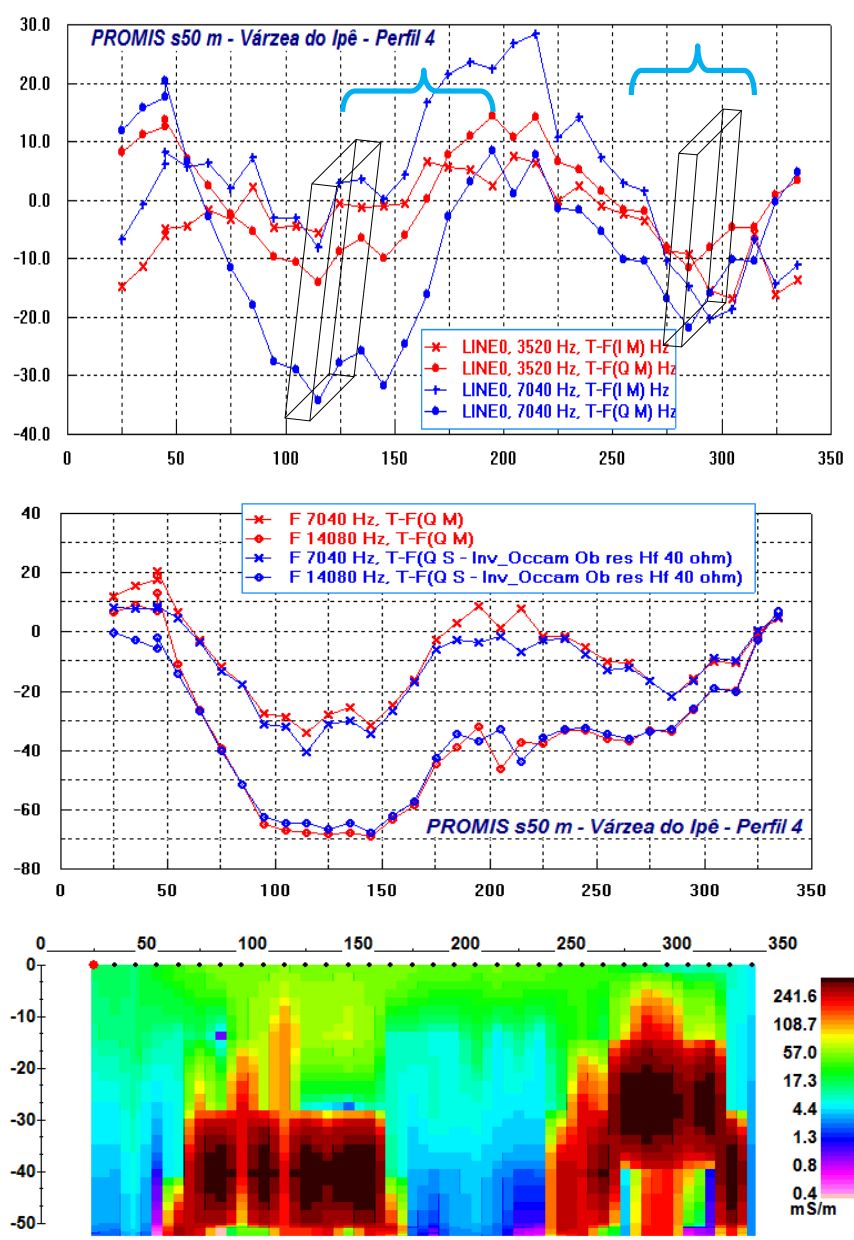

Figura 7 - Sítio Várzea do Ipê, perfil transversal: a) componentes em fase-Ip e quadratura- $Q$ para dados reais; b) comparativo entre as componentes de quadratura para dados reais e dados invertidos, nota-se bom ajuste, com diferença < $5 \%$ em muitos pontos; c) seção do modelo de inversão Occam aplicado aos dados. Fraturas - retângulo, aluvião - entre chaves, azul.

Os dados do EM-34 (Figura 8) indicam valores de condutividade de $38 \mathrm{mS} / \mathrm{m}$ para a configuração de dipolo vertical com o cabo de 40 metros. Não foi empregado o cabo de $20 \mathrm{~m}$. A relação de contraste de condutividade da zona fraturada e aluviões com as rochas cristalinas é menos evidente. Contudo, os picos negativos medidos na configuração de dipolo vertical demonstram a continuidade das estruturas identificadas no Perfil1. Neste caso, as fraturas foram interpretadas nas posições 100 e 140 m (Figura 11).

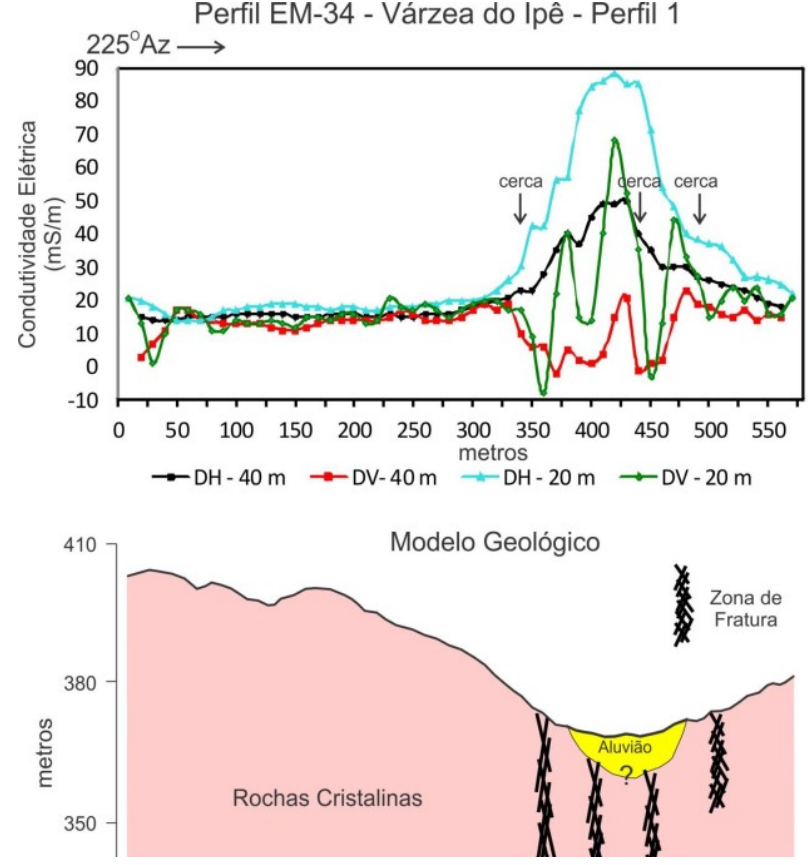

Figura 8 - Dados, interpretação e modelo geológico do Perfil 1 da área de estudo Várzea do Ipê.

Os perfis paralelos ao vale objetivavam investigar estruturas transversais ao vale, associadas às ravinas encaixadas e de comparar os padrões de condutividade elétrica nas encostas e na estrutura principal, preenchida por aluvião. Foram definidas três anomalias principais, associadas a estruturas. As anomalias em X-60 m do perfil na encosta e $\mathrm{X}-125 \mathrm{~m}$ do perfil no vale definem a mesma estrutura de direção NNW-ESSE. No perfil do vale ocorre uma estrutura em X-275 m, com mergulho para NW. Evidencia-se uma terceira estrutura entre X-0 a X_-20 m, que não foi atravessada em sua totalidade, mas observa-se drenagem encaixada em fratura naquela posição. (Figura 8).

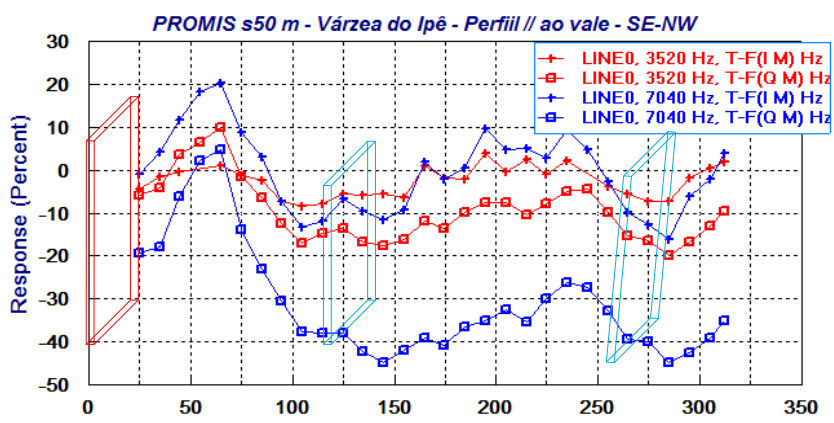

Figura 9 - Sítio Várzea do Ipê, perfil paralelo ao vale principal. Componentes em fase-lp e quadratura- $Q$ para os dados reais. Fraturas interpretadas em retângulo azul e fratura provável em vermelho. 
O EM-34 detectou uma anomalia negativa expressiva em X-60 m na configuração de dipolo vertical, com o cabo de $20 \mathrm{~m}$ (anomalia estreita) e cabo de $40 \mathrm{~m}$ (anomalia larga). Contudo, não ocorre uma assinatura correspondente na configuração de dipolo horizontal, sugerindo que o possível corpo condutivo não apresenta condutividades altas nas partes mais rasas.

No perfil levantado ao longo do aluvião, a variação da condutividade no dipolo horizontal foi interpretada como uma variação na espessura das aluviões. Alternativamente poderia ser interpretado com uma alteração no conteúdo de água, de argila, de salinidade, ou mesmo da interação destes três fatores: cabo de $20 \mathrm{~m}$ (40 a $100 \mathrm{mS} / \mathrm{m})$; cabo de $40 \mathrm{~m}$ (30 a $55 \mathrm{mS} / \mathrm{m})$.

Padrões de fraturas condutivas foram identificadas pelo EM-34 em posições próximas às assinaladas pelo PROMIS, qual seja: X-60 no perfil ao longo da encosta; $\mathrm{X}-100$ ao longo do aluvião.

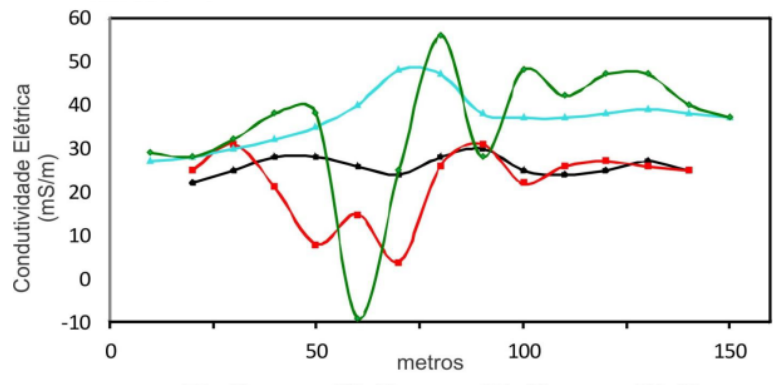

a)
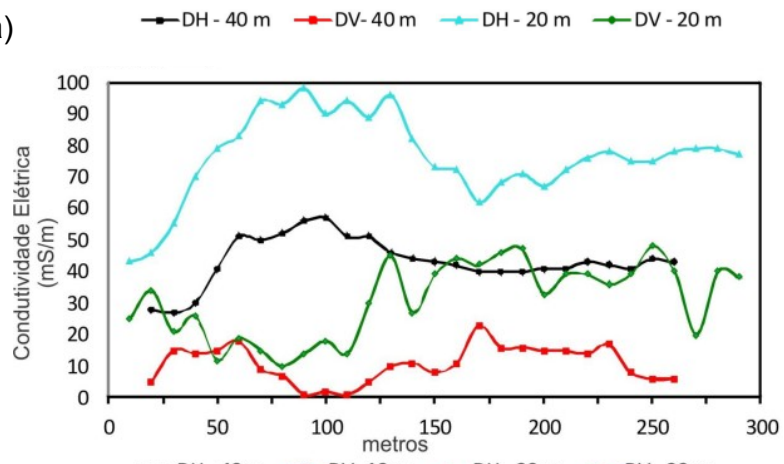

b)

$\rightarrow \mathrm{DH}-40 \mathrm{~m} \rightarrow \mathrm{DV}-40 \mathrm{~m} \rightarrow \mathrm{DH}-20 \mathrm{~m} \rightarrow \mathrm{DV}-20 \mathrm{~m}$

Figura 10 - Dados, interpretação dos perfis na Várzea do Ipê: a) ao longo da encosta; b) no vale.

\section{Discussão e Conclusões}

Os resultados obtidos propiciaram, para algumas comunidades na região de Campina Grande, a seleção de áreas favoráveis à explotação de águas subterrâneas. Nestas, identificaram-se aluviões e sistemas de drenagens bem desenvolvidos, condicionados a megaestruturas orientadas NW-SE e segmentadas por lineamentos NNW-SSE, E-W e NE-SW.

O PROMIS e o EM-34 mostraram-se satisfatórios para os propósitos do trabalho. As limitações para estes equipamentos ocorreram principalmente quando os perfis acompanham redes de energia a menos de $20 \mathrm{~m}$ de distância, quando há cercas a menos de $10 \mathrm{~m}$ destas redes. Linhas de transmissão de alta voltagem alteram leituras a distância inferior a 100 m. Desaconselha-se executar caminhamentos entre cerca distanciadas a menos de $20 \mathrm{~m}$. O EM-34 é menos sensível à presença de cercas.

\section{Agradecimentos}

Os autores agradecem à Secretaria de Recursos Hídricos e à Companhia de Gestão das Águas da Paraíba pela cessão de dados de poços e apoio logístico.

\section{Referências}

Mcneill, J. D., 1980. Eletromagnetic terrain conductivity measurement at low induction numbers. Ontario: GEONICS, 1980. 15p. (Technical Note TN-6).

Milson, J., Brooks, M., Hill, I., 2003. Field Geophysics. West Sussex, England: Editora J. Wiley. Cap. 6, 232p.

Oliveira, R. G. de; Souza Filho, O. A de; Ribeiro, J. A; Oliveira, J. F. de; Veríssimo, L. S., 2002. Área-Piloto do Juá - interpretação e correlação geológica dos dados geofísicos. CPRM/ Projeto Água Subterrânea no Nordeste do Brasil - PROASNE. Relatório Interno. Fortaleza. 35 p. il.

Palacky, G. J., Ritsema, I. L., Jong, S. D., 1981. Electromagnetic prospecting for groundwater in precambrian terrains in the Republic of Upper VOLTA*. Geophysical Prospecting, 29(6), 932-955.

PetRos EiKon, 2011. EMIGMA@/v8.6, software \& manual copyright. PetRos EiKon Inc. 2011, 280 pp.

Pinéo, T. R. G., Branco, R. M. G. C., Cunha, L. S., Souza, M. L., 2014. Airborne and ground geophysics applied to groundwater prospection in hard rocks in Irauçuba, Ceará State, Brazil. Rev. Bras. Geofís., [S.I.], v. 31, n. 4, p. 699 709, maio. ISSN 1809-4511.

Rodrigues, S. W. O., Medeiros, V. C., Marinho, M. S., Oliveira, R. G., 2011. Geologia e recursos minerais da Folha Campina Grande (SB.25-Y-C-I). Brasília: CPRM/SBG, 2011. 101p. Programa Geologia do Brasil.

Telford, W. M., Geldart, L. P., Sheriff, R. E., Keys, D. A., 1984. Applied geophysics. Cambridge University Press, New York, pp 442-457.

Van Dongen, P. and Woodhouse, M., 1994. Finding groundwater: a project manager's guide to techniques and how to use them. Technical Report, UNDPWorldbank Water and Sanitation Program, Worldbank, Washington DC. 